\title{
Factors associated with low birthweight in North Shewa zone, Central Ethiopia: case- control study
}

\author{
Berhanu Gizaw ${ }^{1}$ and Samson Gebremedhin ${ }^{2^{*}}$ (D)
}

\begin{abstract}
Background: Low birthweight (LBW) is an important predictor of neonatal and post neonatal child morality. Though its risk factors have been extensively studied in the developed world; limited epidemiological evidence is available in developing countries including Ethiopia. The purpose of the study is to determine the risk factors of LBW in North Shewa zone, Central Ethiopia.
\end{abstract}

Methods: Unmatched case-control study involving 94 cases and 376 controls was conducted from Jan to Mar 2017 in three public hospitals in the zone. A case was defined as a singleton live birth with birthweight less than $2.5 \mathrm{~kg}$; whereas, a control was a newborn that weighs $2.5-4.0 \mathrm{~kg}$. Cases and controls were recruited on an ongoing basis until the required sample sizes were fulfilled. Data were collected by interviewing mothers, reviewing medical records and measuring the anthropometry of the mothers and the newborns. Bivariable and multivariable logistic regression analyses were used to identify risk factors of LBW. The outputs of the analyses are presented using adjusted odds ratio (AOR) with the respective 95\% confidence interval (CI).

Results: Mothers with no formal education had two times increased odds of delivering LBW babies than women with formal education $[A O R=2.20(95 \% \mathrm{Cl}: 1.11,4.38)]$. Mothers with no history of nutrition counseling during pregnancy had three times increased odds of giving LBW babies than those who were counseled $[A O R=3.35$ (95\% Cl: 1.19, 9.43)]. Non-married women had higher odds of giving LBW newborns as compared to married ones $[A O R=3.54(95 \% \mathrm{Cl}: 1.83,6.83)]$. Mothers from food insecure households had about four times higher odds of LBW as compared to food secure mothers [AOR $=4.42(95 \% \mathrm{Cl}: 1.02,22.25)]$. In contrast to mothers who had the recommended four or more antenatal care (ANC) visits, those who were not booked had three times increased odds of giving to LBW baby [AOR $=3.03$ (95\% Cl: 1.19,7.69)].

Conclusion: Improving the socio-economic status of mothers, enhancing the utilization of ANC and strengthening the integration of nutrition counseling into ANC help to reduce LBW.

Keywords: Low birthweight, Risk factors, Case-control study, North Shewa zone, Ethiopia

\section{Background}

According to the definition of the World Health Organization (WHO), low birthweight (LBW) is weight of an infant at birth of less than $2500 \mathrm{~g}$ irrespective of the gestational age [1]. LBW can result from premature birth (before 37 weeks of gestation) or intrauterine-growth restriction (IUGR), or a combination of the two $[1,2]$. In the developing world, the main cause of LBW is assumed to be

\footnotetext{
* Correspondence: samsongmgs@yahoo.com

${ }^{2}$ School of Public Health, Hawassa University, Hawassa, Ethiopia

Full list of author information is available at the end of the article
}

IUGR; whereas in developed countries prematurity has higher significance $[1,2]$.

Birthweight is the single most important predictor neonatal and post-neonatal survival. It has been estimated that LBW babies are approximately 20 times more likely to die than normal babies in the first year of life [3]. LBW babies are also at increased risk of developing long-term sequels including cognitive developmental delays and decrease of intelligence quotient (IQ) scores [4-7]. The fetal origins hypothesis also suggests that LBW raises the risk

(C) The Author(s). 2018 Open Access This article is distributed under the terms of the Creative Commons Attribution 4.0 International License (http://creativecommons.org/licenses/by/4.0/), which permits unrestricted use, distribution, and reproduction in any medium, provided you give appropriate credit to the original author(s) and the source, provide a link to the Creative Commons license, and indicate if changes were made. The Creative Commons Public Domain Dedication waiver (http://creativecommons.org/publicdomain/zero/1.0/) applies to the data made available in this article, unless otherwise stated. 
of developing some non-communicable diseases later in adulthood life [8-10].

It is estimated that globally 15 to $20 \%$ of all births are LBW, representing more than 20 million births a year [1]. There is considerable variation in the magnitude of LBW across regions and within countries [1]. More than $95 \%$ of LBW babies $-72 \%$ in Asia and in $22 \%$ in Africa - are born in developing countries [1]. The regional estimates of LBW showed that Sub-Saharan Africa is the second, with the regional average of $13 \%$ next to South Asia (28\%) [1, 11]. Hospital-based studies cross-sectional studies conducted in Ethiopia in the last 10 years reported prevalence of LBW ranging from 6 to 23\% [1217]. On the other hand, community-based prospective studies came-up with $9-28 \%$ prevalence [18-22]. In 2012 the United Nations Children's Fund (UNICEF) estimated the national prevalence of LBW was $20 \%$ [23].

LBW is caused by multifold and possibly overlapping factors that affect either the duration of pregnancy or fetal growth, or both $[2,3]$. According to a systematic review [3], the risk factors of LBW can be broadly classified as direct and indirect. Indirect factors include socio-demographic and economic features and maternal age; whereas direct factors comprise: race, maternal height and pre-pregnancy weight, gestational weight gain and calorie intake during pregnancy, perinatal morbidity, paternal anthropometry, parity, infant's sex, alcohol and cigarette exposure during pregnancy and prior history of prematurity or IUGR [3].

Though the risk factors of LBW have been extensively studied in the developed world; there is limited epidemiological evidence in developing countries including Ethiopia. The relative significance of the risk factors is also likely to vary across settings secondary to underlying contextual factors. Accordingly this case-control study was designed to identify factors associated with LBW in North Shewa zone hospitals, central Ethiopia.

\section{Methods}

\section{Study setting}

The study was carried out in three secondary-care public hospitals - Fiche, Kuyu and Dera -found in North Shewa zone, Oromia region, central Ethiopia. As of 2016, North Shewa zone had an estimated population size of 1.5 million. The zone is administratively divided in to 13 districts and has the aforementioned 3 functional hospitals, 62 health centers, 268 health posts. In 2016, the total health facility deliveries in the zone were 38,131 .

\section{Study design and period}

Unmatched case-control study with controls-to-case ratio of 4:1 was conducted from January 01 to March 30, 2017.

\section{Study participants and eligibility criteria}

Singleton live births in the three hospitals during the study period, irrespective of the duration of pregnancy and mode of delivery, were considered eligible for the study. Birthweight of every child was measured and newborns who weigh less than $2.5 \mathrm{~kg}$ were taken as cases; whereas, a similar group of children with a birthweight of 2.5 to $4.0 \mathrm{Kg}$ were categorized as a controls. Multiple births, macrosomic babies (birthweight greater than $4.0 \mathrm{~kg}$ ), mothers or newborns in critical medical conditions and babies weighed more than an hour after birth were excluded.

\section{Sample size determination and sampling approach}

Optimal sample size was determined via the online OpenEpi statistical program [24]. The computation was made using double population proportion formula assuming 95\% confidence level, $80 \%$ power, control-to-case quotient of 4 , and odds ratio (OR) of 2 to be detected as significant. The calculation was separately made for four potential predictors (maternal age $(>/<$ 18 years), place of residence, birth interval $(>/<2$ years $)$ and maternal MUAC $(>/<22 \mathrm{~cm}))$ of LBW and the maximum was taken as the ultimate sample size of the study. The expected proportions of controls exposed for the aformentioned factors were extracted from a study conducted in Southeastern Ethiopia [25]. Ultimately the sample size 94 cases and 376 controls was determined. Between Jan to Mar 2017, cases and controls were recruited on an ongoing basis until the required sample size was fulfilled for both groups.

\section{Data collection tools and procedures}

The data were collected by interviewing the mothers, reviewing medical records and measuring the anthropometry of the mothers and the newborns.

Six trained midwives working in the delivery wards of the three hospitals collect the data using structured and pretested questionnaire prepared in Afan Oromo language. Eligible mothers were interviewed face to face within $24 \mathrm{~h}$ after delivery. Socio-demographic and economic information was assessed using standard questions extracted from the DHS questionnaire [26].

The medical records of the mothers were reviewed and relevant information including last-normal menstrual period and ultrasound dating of pregnancy were extracted to the questionnaire.

The frequency of consumption of eleven major food groups during the pregnancy was measured using a Food Frequency Questionnaire (FFQ) based on the mothers' recall. On the other hand, the level of household food insecurity was assessed using the Household Food Insecurity Access Scale (HFIAS) of the Food and Nutrition Technical Assistance (FANTA) project. The scale 
categorized the subjects into four ordinal groups - secure; mild, moderate and severe insecurity [27].

The weight of the newborns was measured within the first hour of birth using a calibrated Seca scale and rounded to the nearest $100 \mathrm{~g}$. MUAC of mother was measured to the nearest $0.1 \mathrm{~cm}$ using MUAC tape. Anthropometric measurements were taken in duplicates by an observer and ultimately the average of the duplicates was registered.

\section{Variables of the study}

The independent variables of the study include socio-demographic factors (maternal age, education, occupation, wealth index, residence, marital status, religion, ethnicity), reproductive factors (gestational age, prior history of LBW, parity, birth-to-birth interval, utilization of antenatal care (ANC), reported illness during pregnancy), nutritional factors (maternal MUAC, household food security status, exposure to nutrition counseling during the pregnancy, frequency of consumption of major food groups, restriction of diet during pregnancy due to food taboo, history prenatal iron supplementation), work load during pregnancy and infant's sex. The dependent variable was birthweight status dichotomized into LBW or normal birthwieght.

\section{Data management and analysis}

The collected data were checked for completeness, coded and entered into Epi info version-3.5, and then exported to the Statistical Package for Social Sciences (SPSS), version 20 for analysis.

Wealth index was computed as a composite indicator of living standard based on ownership of selected household assets, size of agricultural land, number of livestock owned, materials used for housing construction, and ownership of improved water and sanitation facilities. The analysis was made using the Principal Component Analysis (PCA). The generated principal component was divided into three wealth classes.

The socio-demographic and other background profiles of the cases and controls were compared using chi-square test. Prior to analysis the assumptions of chi-square test were checked. When smaller expected frequencies were encountered, re-categorization of variables or merger of the levels was made.

Factors associated with LBW were identified using bivariable and multivariable logistic regression models. Independent variables that demonstrated near to statistically significant association ( $p$-value less than 0.25$)$ with the outcome variable in the bivariable models, were considered as candidate variables for the multivariable logistic regression models. In order to reduce over adjustment bias, direct and indirect predictors of LBW were fitted separately into two multivariable models [3].
In the ultimate multivariable models the level of multicolinearity was evaluated using variance inflation factor and found within a tolerable range. The goodness-of-fit assessed using Hosmer-Lemeshow test.

\section{Ethical considerations}

The study was approved by the Institutional Review Board (IRB) of College of Medicine and Health Sciences, Hawassa University. Data were collected after taking informed consent from the mothers.

\section{Results}

\section{Socio-demographic characteristics of the study participants}

A total of 470 mother-newborn dyads comprising 94 cases and 376 controls were included in the study. The mean $( \pm \mathrm{SD})$ age of the mothers of the cases was 27.4 $( \pm 6.6)$ years and that of mothers of the controls was $29.0( \pm 6.4)$ years. About two-fifth (41.5\%) of the mothers of the cases and about a quarter $(27.7 \%)$ of that of the controls were in the age group 15-24 years and the difference was significant $(p=0.027)$. Higher proportion of the mothers of the cases $(53.2 \%)$ had no formal education than that of the controls $(42.0 \%)(p=0.002)$. The two groups were significantly different in terms of ethnicity, religious affiliation and marital status $(p<0.05)$. However, there were no significant variations based on household wealth index, place of residence and maternal employment status $(p>0.05)$ (Table 1$)$.

\section{Reproductive characteristics}

Regarding the reproductive profile, more cases $(16.0 \%)$ were preterm births than the controls $(5.9 \%)(p=0.001)$. Among mothers who had at least two births, short birth-to-birth interval (less than 2 years) was observed in $52.8 \%$ of the cases and $21.2 \%$ of the controls $(p<$ 0.001). Among mothers of the cases, $25.5 \%$ had no ANC visits as compared to $13.8 \%$ in that of the controls $(p<$ 0.001). Significant differences were also observed between the groups in the number of ANC consultations $(p<0.001)$. However, the mothers of cases and controls were not significantly different in terms of parity, presence of pregnancy related complications $(p=0.403)$ and infant's sex $(p=0.781)$ (Table 2).

\section{Nutrition related characteristics of the study participants}

Nearly half $(44.9 \%)$ of mothers of the cases and $58.5 \%$ of that of the controls received no nutrition counseling during the pregnancy $(p=0.019)$. In contrast to $42.3 \%$ of the mothers of the control babies, $28.0 \%$ of mothers of the cases had taken prenatal iron supplements $(p=$ 0.009). About half (52.1\%) of the households of the controls were food secure but the corresponding figure was significantly lower $(26.6 \%)$ in the cases group $(p<0.001)$. 
Table 1 Socio-demographic characteristics of the mothers who gave birth in North Shewa zone hospitals, Central Ethiopia, 2017

\begin{tabular}{|c|c|c|c|c|c|}
\hline \multirow[t]{2}{*}{ Variables } & \multicolumn{2}{|c|}{ Cases $(n=94)$} & \multicolumn{2}{|c|}{ Controls $(n=376)$} & \multirow[t]{2}{*}{$p$-value } \\
\hline & Number & Percent & Number & Percent & \\
\hline \multicolumn{6}{|l|}{ Maternal age (years) } \\
\hline $15-24$ & 39 & 41.5 & 104 & 27.7 & \multirow[t]{3}{*}{$0.027^{*}$} \\
\hline $25-34$ & 38 & 40.4 & 200 & 53.2 & \\
\hline $35-49$ & 17 & 18.1 & 72 & 19.1 & \\
\hline \multicolumn{6}{|l|}{ Place of residence } \\
\hline Rural & 59 & 62.8 & 230 & 61.2 & \multirow[t]{2}{*}{0.776} \\
\hline Urban & 35 & 37.2 & 146 & 38.8 & \\
\hline \multicolumn{6}{|l|}{ Maternal educational status } \\
\hline No formal education & 50 & 53.2 & 163 & 42 & \multirow[t]{3}{*}{$0.002^{*}$} \\
\hline Primary school & 29 & 30.9 & 83 & 22.1 & \\
\hline Secondary or tertiary education & 15 & 16 & 130 & 34.6 & \\
\hline \multicolumn{6}{|l|}{ Religion } \\
\hline Orthodox Christian & 62 & 66 & 306 & 81.4 & \multirow[t]{3}{*}{$<0.001^{*}$} \\
\hline Protestant & 22 & 23.4 & 33 & 8.8 & \\
\hline Muslim & 10 & 9.6 & 33 & 8.8 & \\
\hline \multicolumn{6}{|l|}{ Ethnicity } \\
\hline Oromo & 79 & 84 & 346 & 92.0 & \multirow[t]{3}{*}{$0.044^{*}$} \\
\hline Amhara & 10 & 10.6 & 23 & 6.1 & \\
\hline Others & 5 & 5.3 & 7 & 1.9 & \\
\hline \multicolumn{6}{|l|}{ Occupation } \\
\hline Employed/Merchant & 27 & 28.7 & 126 & 33.5 & \multirow[t]{3}{*}{0.376} \\
\hline Housewife & 66 & 70.2 & 244 & 64.9 & \\
\hline Others & 1 & 1.1 & 6 & 1.6 & \\
\hline \multicolumn{6}{|l|}{ Wealth index } \\
\hline Poorest or poorer & 38 & 40.4 & 150 & 39.9 & \multirow[t]{3}{*}{0.911} \\
\hline Middle & 20 & 21.3 & 74 & 19.7 & \\
\hline Richer or richest & 36 & 38.3 & 152 & 40.4 & \\
\hline \multicolumn{6}{|l|}{ Marital status } \\
\hline Married & 73 & 77.7 & 346 & 92.0 & \multirow[t]{2}{*}{$<0.001^{*}$} \\
\hline Others & 21 & 22.3 & 30 & 8.0 & \\
\hline
\end{tabular}

*Statistically significant difference at $p$-value of 0.05

The two groups were not significantly different based on reported practice of food taboo during pregnancy and prevalence of thinness (MUAC less than $210 \mathrm{~mm}$ ) (Table 3).

The overall dietary intake of the mothers was assessed using a FFQ. However, the cases and controls were not significantly different in the frequency of consumption of 11 food groups. The food groups which considered in the study were: cereals, roots and tubers, legumes, milk and milk products, flesh foods, eggs, vitamin A rich fruits and vegetables, other fruits, other vegetables, sweets and condiments.

\section{Risk factors of low birthweight}

As it was stated earlier, risk factors of LBW were identified by fitting two different multivariable regression models for the direct and indirect predictors of birthweight. The variables were classified into the two blocks according to the Kramer's framework [3].

For the indirect model, six socio-demographic variables (maternal age, place of residence, maternal education, occupation of the mother, household wealth index, religion, ethnicity and marital status) were considered. Among these, based on bivariable logistic regression analyses, six variables presented in Table 5 had $p$-value less than 0.25 hence fitted into the multivarible model.

The ultimate analysis showed the odds of LBW were increased by two fold in the mothers with no formal education as compared to their counterparts. Those who were not married had three times elevated odds of LBW as compared to married mothers. Protestant Christians had three times increased odds of LBW than Orthodox Christians (Table 4). 
Table 2 Reproductive characteristics of the mothers who gave birth in North Shewa zone hospitals, Central Ethiopia, December 25, 2016-March 29, 2017

\begin{tabular}{|c|c|c|c|c|c|}
\hline \multirow[t]{2}{*}{ Variables } & \multicolumn{2}{|c|}{ Cases $(n=94)$} & \multicolumn{2}{|c|}{ Controls $(n=376)$} & \multirow[t]{2}{*}{$p$-value } \\
\hline & Number & Percent & Number & $\overline{\text { Percent }}$ & \\
\hline \multicolumn{6}{|c|}{ Gestational age (in weeks) } \\
\hline$<37$ & 15 & 16.0 & 22 & 5.9 & \multirow[t]{2}{*}{$0.001^{*}$} \\
\hline$\geq 37$ & 79 & 84 & 354 & 94.1 & \\
\hline \multicolumn{6}{|l|}{ Parity } \\
\hline Primipara & 41 & 43.6 & 135 & 35.9 & \multirow[t]{2}{*}{0.167} \\
\hline Parous & 53 & 56.4 & 241 & 64.1 & \\
\hline \multicolumn{6}{|l|}{ Birth-to-birth interval } \\
\hline Less than two years & 28 & 52.8 & 51 & 21.1 & \multirow[t]{2}{*}{$<0.001$} \\
\hline Two or more years & 25 & 47.2 & 190 & 78.8 & \\
\hline \multicolumn{6}{|c|}{ ANC during the current pregnancy } \\
\hline No ANC & 24 & 25.5 & 52 & 13.8 & \multirow[t]{3}{*}{$<0.001^{*}$} \\
\hline $1-3$ visits & 63 & 67.1 & 237 & 63.1 & \\
\hline 4 or more visits & 7 & 7.4 & 87 & 23.1 & \\
\hline \multicolumn{6}{|l|}{ Trimester at first ANC } \\
\hline First & 8 & 11.4 & 26 & 8.0 & \multirow[t]{3}{*}{$<0.001^{*}$} \\
\hline Second & 38 & 54.3 & 273 & 84.3 & \\
\hline Third & 24 & 34.3 & 25 & 7.7 & \\
\hline \multicolumn{6}{|l|}{ Pregnancy complications } \\
\hline No & 86 & 91.5 & 353 & 93.9 & \multirow[t]{2}{*}{0.403} \\
\hline Yes & 8 & 8.5 & 23 & 6.1 & \\
\hline \multicolumn{6}{|l|}{ Infant's sex } \\
\hline Female & 45 & 47.9 & 174 & 46.3 & \multirow[t]{2}{*}{0.781} \\
\hline Male & 49 & 52.1 & 202 & 53.7 & \\
\hline
\end{tabular}

*Statistically significant difference at $p$-value of 0.05

For the direct model, ten variables (namely gestational age, parity, number of ANC visits, presence of pregnancy related complications, infant's sex, restriction of diet due to food taboos, dietary counseling in the index pregnancy, use of iron supplements in the pregnancy, MUAC of the mother, and household food security status) were considered. Among them, based on bivariable analysis, five variables presented in Table 5 had $p$-value less than 0.25 and hence subjected to the multivariable analysis.

The ultimate model showed that mothers who have no history of nutrition counseling during the pregnancy had more than three folds increased odds of delivering LBW babies than those who got counseling. Mothers from food insecure households had about four times higher odds of LBW as compared to food secure mothers. Taking mothers who had the recommended four or more ANC visits as reference, those who were not booked had three times increased odds of giving to LBW baby (Table 5).

\section{Discussion}

This study identified socio-demographic, reproductive and nutrition related risk factors of LBW. From
Table 3 Nutritional and household food security profile of the mothers of the cases and controls, North Shewa zone hospitals, Central Ethiopia, 2017

\begin{tabular}{|c|c|c|c|c|c|}
\hline \multirow[t]{2}{*}{ Variables } & \multicolumn{2}{|c|}{ Cases $(n=94)$} & \multicolumn{2}{|c|}{ Controls $(n=376)$} & \multirow[t]{2}{*}{$p$-value } \\
\hline & Number & Percent & Number & Percent & \\
\hline \multicolumn{6}{|c|}{ Restriction of diet due to food taboos } \\
\hline No & 89 & 94.7 & 368 & 97.9 & 0.091 \\
\hline Yes & 5 & 5.3 & 8 & 2.1 & \\
\hline \multicolumn{6}{|c|}{ Nutrition counseling during pregnancy } \\
\hline Yes & 39 & 41.5 & 207 & 55.1 & $0.019^{*}$ \\
\hline No & 55 & 58.5 & 169 & 44.9 & \\
\hline \multicolumn{6}{|c|}{ Use of iron tablets in recent pregnancy } \\
\hline No & 68 & 72.3 & 217 & 57.7 & $0.009^{*}$ \\
\hline Yes & 26 & 27.7 & 159 & 42.3 & \\
\hline \multicolumn{6}{|c|}{ MUAC of mother (mm) } \\
\hline$<210$ & 36 & 38.3 & 122 & 38.4 & 0.283 \\
\hline$\geq 210$ & 58 & 61.7 & 254 & 67.6 & \\
\hline \multicolumn{6}{|c|}{ Household food security status } \\
\hline Secure & 25 & 26.6 & 196 & 52.1 & $<0.001^{*}$ \\
\hline Insecurity & 69 & 73.7 & 180 & 47.9 & \\
\hline
\end{tabular}

*Statistically significant difference at $p$-value of 0.05

socio-demographic factors, absence of formal maternal education and unmarried marital status were significant predictors of LBW. Further, mothers who did not receive nutrition counseling during pregnancy and those who were from food insecure households were at increased odds of LBW.

We found that mothers with no formal education had increased odds of giving to LBW newborns. This is parallel to the findings of studies conducted South-East Ethiopia [25], rural Sidama, Southern Ethiopia [18], India [28, 29] and Tanzania [30]. This can be explained by the fact that formal education enables women to improve their capacity to generate income and to promote optimal dietary practices during pregnancy. Further it may also enhance their awareness about other risk factors of LBW. Education enables women to make independent decisions and to have better access to household resources that are important for better nutrition [31].

Being married was identified as a protective factor from LBW. Reasonable number of studies witnessed that the general health of married women is better than that of unmarried ones [32, 33]. Unmarried women may experience higher stress than married mothers because of less stable relationships. Further married mothers may get socio-economic supports from their husbands so that they will not be under such pressure. This finding is in agreement with a study conducted in Tanzania which observed that unmarried 
Table 4 Socio-demographic factors associated with low birthweight among deliveries in North Shewa zone hospitals, Central Ethiopia, 2017

\begin{tabular}{|c|c|c|c|c|}
\hline \multirow[t]{2}{*}{ Variables } & \multirow{2}{*}{$\begin{array}{l}\text { Cases } \\
(n=94)\end{array}$} & Controls & \multirow[t]{2}{*}{ COR (95\% Cl) } & \multirow[t]{2}{*}{ AOR $(95 \% \mathrm{Cl})$} \\
\hline & & $(n=376)$ & & \\
\hline \multicolumn{5}{|l|}{ Age in years } \\
\hline $15-24$ & 39 & 104 & $1.59(0.83,3.02)$ & $0.54(0.27-1.06)$ \\
\hline $25-34$ & 38 & 200 & $0.81(0.43,1.51)$ & $1.21(0.60-2.46)$ \\
\hline $35-49$ & 17 & 72 & $1^{r}$ & $1^{r}$ \\
\hline \multicolumn{5}{|l|}{ Residence } \\
\hline Rural & 59 & 230 & $1^{r}$ & $1^{r}$ \\
\hline Urban & 35 & 146 & $0.94(0.59,1.49)$ & $0.66(0.16-2.70)$ \\
\hline \multicolumn{5}{|l|}{ Educational status } \\
\hline No formal education & 50 & 163 & $0.88(0.52,1.49)$ & $2.20(1.11-4.38)^{*}$ \\
\hline Primary school or above & 29 & 83 & $1^{r}$ & $1^{r}$ \\
\hline \multicolumn{5}{|l|}{ Occupation } \\
\hline Employed /merchant & 27 & 126 & $1^{r}$ & - \\
\hline Housewife & 66 & 244 & $1.26(0.77,2.07)$ & - \\
\hline \multicolumn{5}{|l|}{ Wealth index } \\
\hline Poorest or poorer & 38 & 150 & $1.07(0.64,1.78)$ & - \\
\hline Middle & 20 & 74 & $1.14(0.62,2.11)$ & - \\
\hline Richer or richest & 36 & 152 & $1^{r}$ & - \\
\hline \multicolumn{5}{|l|}{ Marital status } \\
\hline Married & 73 & 346 & $1^{r}$ & $1^{r}$ \\
\hline Others & 21 & 30 & $3.32(1.80,6.12)^{*}$ & $3.54(1.83-6.83)^{*}$ \\
\hline \multicolumn{5}{|l|}{ Religion } \\
\hline Orthodox Christian & 62 & 306 & $1^{r}$ & $1^{r}$ \\
\hline Muslim & 10 & 33 & $1.50(0.70-3.19)$ & $1.23(0.54-2.81)$ \\
\hline Protestant & 22 & 33 & $3.29(1.80-6.02)^{*}$ & $3.43(1.73-6.80)^{*}$ \\
\hline \multicolumn{5}{|l|}{ Ethnicity } \\
\hline Oromo & 79 & 346 & $0.52(0.24-1.15)$ & $0.53(0.24,1.15)$ \\
\hline Others & 5 & 7 & $1.64(0.42-6.44)$ & $1.64(0.42,6.45)$ \\
\hline Amhara & 10 & 23 & $1^{r}$ & $1^{r}$ \\
\hline
\end{tabular}

$1^{r}$ Reference group; ${ }^{*}$ Significant association at $p$-value of 0.05 ; -The variable was not included in the multivariable model

mothers were almost two times more likely to give birth to LBW neonates [31]. A systematic review concluded unmarried mothers have significantly higher risks of LBW and preterm births [34].

The analysis indicated that Protestant Christians had three times increased odds of LBW than Orthodox Christians. Though religious affiliation can theoretically affect dietary habits and food restrictions during pregnancy, we are not aware of the presence of such variations between the two groups in the area. The observed association possibly might have emanated from residual confounding from socioeconomic differences between the groups. Further, as the number of Protestants in the analysis was relatively small, chance could also explained the association.
In this study, the odds of delivering LBW babies were higher among mothers who did not receive nutrition education during the pregnancy as compared to their counterparts. Previous studies have indicated that nutrition education and counseling during pregnancy benefits in reducing preterm and LBW births [35]. An interventional study in Bangladesh demonstrated that regular prenatal nutrition counseling enhances maternal weight gain during the third trimester and increases birthweight of the newborn by $0.4 \mathrm{~kg}$ [36]. This may imply that stronger integration of nutrition education into perinatal care may contribute to reducing the risk of LBW.

We observed that food insecure mothers had four fold increased odds of giving birth to LBW babies than their counterparts. Intuitively, food insufficiency increases risk 
Table 5 Reproductive and nutrition related factors associated with low birthweight, North Shewa zone hospitals, Central Ethiopia, 2017

\begin{tabular}{|c|c|c|c|c|}
\hline \multirow[t]{2}{*}{ Variables } & \multirow{2}{*}{$\begin{array}{l}\text { Cases } \\
(\mathrm{n}=94)\end{array}$} & Controls & \multirow[t]{2}{*}{ COR $(95 \% \mathrm{Cl})$} & \multirow[t]{2}{*}{$\mathrm{AOR}(95 \% \mathrm{Cl})$} \\
\hline & & $(n=376)$ & & \\
\hline \multicolumn{5}{|l|}{ Gestational age } \\
\hline$<37$ weeks & 15 & 22 & $3.06(1.52,6.15)^{*}$ & $3.70(0.42,33.33)$ \\
\hline$\geq 37$ weeks & 79 & 354 & $1^{r}$ & $1^{\mathrm{r}}$ \\
\hline \multicolumn{5}{|l|}{ Parity } \\
\hline Primiparous & 41 & 135 & $1.38(0.87,2.19)$ & - \\
\hline Multiparous & 53 & 241 & $1^{r}$ & - \\
\hline \multicolumn{5}{|c|}{ ANC during the current pregnancy } \\
\hline No ANC & 24 & 52 & $5.73(2.31,14.24)^{*}$ & $3.03(1.19,7.69)^{*}$ \\
\hline $1-3$ visits & 63 & 237 & $3.30(1.46,7.49)^{*}$ & $3.13(0.99,9.10)$ \\
\hline 4 or more visits & 7 & 87 & $1^{r}$ & $1^{r}$ \\
\hline \multicolumn{5}{|c|}{ Presence of pregnancy complications } \\
\hline No & 86 & 353 & $0.72(0.31,1.66)$ & - \\
\hline Yes & 8 & 23 & $1^{r}$ & - \\
\hline \multicolumn{5}{|l|}{ Infant's sex } \\
\hline Female & 45 & 174 & $1.07(0.68,1.68)$ & - \\
\hline Male & 49 & 202 & $1^{\mathrm{r}}$ & - \\
\hline \multicolumn{5}{|c|}{ Avoidance of food due to food taboos } \\
\hline No & 89 & 368 & $0.39(0.12,1.21)$ & $0.31(0.06,1.58)$ \\
\hline Yes & 5 & 8 & $1^{r}$ & $1^{r}$ \\
\hline \multicolumn{5}{|c|}{ Dietary counseling during pregnancy } \\
\hline Yes & 39 & 207 & $1^{r}$ & $1^{r}$ \\
\hline No & 55 & 169 & $1.73(1.09,2.73)^{*}$ & $3.35(1.19,9.43)^{*}$ \\
\hline \multicolumn{5}{|l|}{ Use of iron tablets } \\
\hline No & 68 & 217 & $1^{\mathrm{r}}$ & $1^{r}$ \\
\hline Yes & 26 & 159 & $0.52(0.32,0.86)$ & $0.58(0.19,1.78)$ \\
\hline \multicolumn{5}{|c|}{ MUAC of mother (mm) } \\
\hline$<210$ & 36 & 122 & $1.29(0.81,2.06)$ & - \\
\hline$\geq 210$ & 58 & 254 & $1^{r}$ & - \\
\hline \multicolumn{5}{|l|}{ Food security status } \\
\hline Secure & 25 & 196 & $1^{r}$ & $1^{r}$ \\
\hline Insecure & 69 & 180 & $3.01(1.82,4.96)^{*}$ & $4.42(1.02,22.25)^{*}$ \\
\hline
\end{tabular}

$1^{\mathrm{r}}$ Reference group; * Significant association at $p$-value of 0.05 ; -The variable was not included in the multivariable model

LBW by compromising maternal nutrient intake, pre-pregnancy weight and gestational weight gain rate. A similar pattern of association has been appreciated by studies conducted in Ethiopia and abroad [37, 38]. For instance, a case-control study in Addis Ababa, Ethiopia concluded that mothers in food insecure household were 3.6 times more likely to have LBW newborns [37].

The results suggest that frequent $A N C$ reduces the risk of LBW. The benefit of ANC could emanate from its various components including prevention and management of anemia and other pregnancy complications. Previous studies came up with conflicting findings. A systematic review concluded that prenantal care prevents neither preterm birth nor IUGR [39]. On the other hand, preterm delivery which is more common in mothers having LBW babies may limit the number of late $\mathrm{ANC}$ visits and induce spurious association between ANC and LBW.

The findings of the study should be interpreted in consideration of the following methodological shortcomings. As the study employed a retrospective design, recall errors in the measurement of exposures (e.g. frequency of consumption of different food groups or events related to household food insecurity) are possible. Such errors 
are likely to produce misclassification of exposures and ultimately may underestimate the strength of associations. Further, as any observational study, residual confounding from unmeasured or misclassified variables cannot be ruled out.

For some of the potential risk factors including gestational age, practice of food taboo and occurrence of pregnancy complications, the observed frequencies were low and this might have reduced the statistical power to detect actual differences. Further, due to the case-control nature of the study, we did not measure some potentially predictors of LBW including prepregnancy weight, gestational weight gain and paternal anthropometry. As study was restricted to hospitals the findings may not be fully generalizable to the entire births in the locality.

\section{Conclusion}

The study demonstrated that maternal educational status, marital status, exposure to nutrition counseling during pregnancy and household food insecurity were significant predictors of LBW. Improving the socio-economic status of mothers, expansion of the utilization of ANC and strengthening the integration of nutrition counseling into ANC help to reduce LBW.

\section{Abbreviations \\ ANC: Antenatal care; AOR: Adjusted odds ratio; Cl: Confidence interval; COR: Crude odds ratio; DHS: Demographic and health survey; FANTA: Food and nutrition technical assistance; FFQ: Food frequency questionnaire; HFIAS: Household food insecurity access scale; IQ: Intelligence quotient; IRB: Institutional review board; IUGR: Intrauterine growth restriction; LBW: Low birthweight; MUAC: Mid-upper arm circumstance; PCA : Principal component analysis; SPSS: Software package for social sciences; UNICEF: United Nations Children's Fund; WHO: World Health Organization}

\section{Acknowledgements}

We are grateful for the financial support of Hawassa University for conducting the study. We would like to sincerely acknowledge the mothers for consenting for the study. Our acknowledgements also go to the data collectors of the study and the administrators of the three hospitals.

\section{Funding}

This study was made possible by the financial support of Hawassa University, Ethiopia.

\section{Availability of data and materials}

The dataset analyzed is available from the corresponding author on reasonable request.

\section{Authors' contributions}

BG conceived and designed the study; collected, analyzed and interpreted the data; and drafted the manuscript. SG supervised the overall process of the research. Both authors critically reviewed the manuscript for intellectual content and approved the final manuscript.

\section{Ethics approval and consent to participate}

The study was approved by the IRB of College of Medicine and Health Sciences, Hawassa University. Data were collected after taking informed consent from the mothers.

\section{Consent for publication}

Not applicable.

\section{Competing interests}

The authors declare that they have no competing interests.

\section{Publisher's Note}

Springer Nature remains neutral with regard to jurisdictional claims in published maps and institutional affiliations.

\section{Author details}

${ }^{1}$ Department of Public Health, Selale University, Salale, Ethiopia. ${ }^{2}$ School of Public Health, Hawassa University, Hawassa, Ethiopia.

Received: 12 March 2018 Accepted: 21 June 2018

Published online: 04 July 2018

\section{References}

1. United Nations Children's Fund, World Health Organization. Low birth weight: country, regional and global estimates. New York: UNICEF; 2004.

2. Kramer MS. Determinants of low birth weight: methodological assessment and meta-analysis. Bull World Health Organ. 1987;65(5):663-737.

3. Kramer MS. Intrauterine growth and gestational duration determinants. Pediatr. 1987;80(4):502-11.

4. Siegel LS. The long-term prognosis of pre-term infants. Hum Nat. 1994;5(1): 103-26.

5. Conley D. Bennet NG. Is biology destiny? Birth weight and life chances. Am Sociol Rev. 2000;65(3):458-67.

6. Pallotto EK, Kilbride HW. Perinatal outcome and later implications of intrauterine growth restriction. Clin Obstet Gynecol. 2006;49(2):257-69.

7. Kormos CE, Wilkinson AJ, Davey CJ, Cunningham AJ. Low birth weight and intelligence in adolescence and early adulthood: a meta-analysis. J Public Health. 2014;36(2):213-24.

8. Calkins K, Devaskar SU. Fetal origins of adult disease. Curr Probl Pediatr Adolescent Health Care. 2011;41(6):158-76.

9. Barker DJP, Osmond C, Kajantie E, Eriksson J. Growth and chronic disease: findings in the Helsinki birth cohort. Ann Hum Biol. 2009;36:445-58.

10. Reyes L, Manalich R. Long-term consequences of low birth weight. Kidney Int. 2005;68(Suppl 97):107-11.

11. World Health Organization. Global Targets 2025: To improve maternal, infant and young child nutrition. Accessed from http://www.who.int/ nutrition/global-target-2025/en/: Accessed 19 Jan 2017.

12. Teklehaimanot N, Hailu T, Assefa H. Prevalence and factors associated with low birth weight in Axsum and Laelay Maichew districts, North Ethiopia: a comparative cross sectional study. Int J Nutr Food Sci. 2014;3(6):560-6.

13. Adane AA, Ayele TA, Ararsa LG, Bitew BD, Zeleke BM. Adverse birth outcomes among deliveries at Gondar University hospital, north West Ethiopia. BMC Pregnancy Childb. 2014;14(90):2014.

14. Eshete A, Birhanu D, Wassie B. Birth outcomes among laboring mothers in selected health facilities of north Wollo zone, Northeast Ethiopia: a facility based cross-sectional study. Sci Res Publishing - Health. 2013;5(7):1141-50.

15. Gebremedhin M, Ambaw F, Admassu E, Berhane H. Maternal associated factors of low birth weight: a hospital based cross-sectional mixed study in Tigray, Northern Ethiopia. BMC Pregnancy Childb. 2015;15:222.

16. Zeleke BM, Zelalem M, Mohammed N. Incidence and correlates of low birth weight at a referral hospital in Northwest Ethiopia. Pan Afr Med J. 2012;12:4.

17. Tema T. Prevalence and determinants of low birthweight in Jimma zone southwestern Ethiopia. East Afr Med J. 2006;83(7):366-71.

18. Gebremedhin S, Enquselassie F. Umeta M.2012.Independent, and joint effects of prenatal zinc and vitamin a deficiency on bitthweight in rural Sidama, Sothern Ethiopia: prospective cohart study. PLoS One. 2012;7(12): e50213.

19. Wado YD, Afework MF, Hindin MJ. Effect of maternal pregnancy intensions depressive symptoms and social support on risk of low birth weight: a prospective study from south western Ethiopia. PLoS One. 2014;9(5):e96304.

20. Assefa N, Berhane $Y$, Worku A. Wealth status, mid upper arm circumference (MUAC) and antenatal care are determinants for low birth weight in Kersa, Ethiopia. PLoS One. 2012;7(6):e39957.

21. Zerfu TA, Umeta M, Baye K. Dietary diversity during pregnancy is associated with reduced risk of maternal anemia, preterm delivery, and low birth weight in a prospective cohort study in rural Ethiopia. Am J Clin Nutr. 2016; 103(6):1482-8. 
22. Central Statistical Agency [Ethiopia] and the DHS Program. Ethiopia: demographic and health survey 2016. Rockville, Maryland and Addis Ababa, Ethiopia: CSA and ICF; 2017.

23. Unicef. Ethiopia: Statistics. Accessed from https://data.unicef.org/resources/lowbirthweight-country-regional-and-global-estimates/. Accessed 19 Jan 2017.

24. Dean AG, Sullivan KM, Soe MM. OpenEpi: Open Source Epidemiologic Statistics for Public Health Accessed from https://www.openepi.com/Menu/ OE_Menu.htm. Accessed 14 Jan 2016.

25. Demelash H, Motbainor A, Nigatu D, Gashaw K, Melese A. Risk factors for low birth weight in bale zone hospitals, south-East Ethiopia : a case-control study. BMC Pregnancy Childb. 2015;15:264

26. The DHS Program. DHS model questionnaires. Accessed from: https:// dhsprogram.com/What-We-Do/Survey-Types/DHS-Questionnaires.cfm. Accessed 17 Dec 2017.

27. Coates J, Swindale A, Bilinsky P. Household food insecurity access scale (HFIAS) for measurement of food access: Indicator guide. New York: FANTA; 2007.

28. Jayant D, Phalke D, Bangal V, Peeyuusha D, Sushen B. Maternal risk factors for low birthweight neonates: a hospital based case control studyin rural area of western Maharashtra,India. Natl J Commun Med. 2011;2(3):394-8.

29. Mumbare SS, Maindarkar G, Darade R, Yenge S, Tolani MK, Patolie K. Maternal risk factors associated with term low birth weight neonates: a matched-pair case control study. Indian Pediatr. 2011;49(1):25-8.

30. Siza JE. Risk factors associated with low birth weight of neonates among pregnant women attending a referral hospital in northern Tanzania. Tanzania J Health Res. 2008:10(1):1-8.

31. Girma W, Genebo T. Determinants of nutritional atatus of women and children in Ethiopia. Calverton: ORC Macro; 2002.

32. Robards J, Evandrou M, Falkingham J, Vlachantoni A. Marital status, health and mortality. Maturitas. 2012;73(4):295-9.

33. Joung IM. The relationship between marital status and health. Ned Tijdschr Geneeskd. 1997;141(6):277-82.

34. Shah PS, Zao J, Ali S. Maternal marital status and birth outcomes: a systematic review and meta-analyses. Matern Child Health J. 2011;15(7):1097-109.

35. Institute of Health Economics. Determinants and prevention of low birth weight: a synopsis of the evidence. Alberta Canada: IHE; 2008.

36. Akter SM, Roy SK, Thakur SK, Sultana M, Khatun W, Rahman R, et al. Effects of third trimester counseling on pregnancy weight gain, birthweight, and breastfeeding among urban poor women in Bangladesh. Food Nutr Bull. 2012;33(3):194-201.

37. Deyessa N, Firdu N, Sahlu D. The relationship between low birth weight and household food insecurity in Addis Ababa, Ethiopia. A case control study [Master's thesis]. Accessed from: http://etd.aau.edu.et/handle/123456789/ 16286. Accessed 17 Dec 2017.

38. Hromi-Fiedler A. Nutrient intakes, food insecurity, pregnancy weight gain and birth outcomes among Connecticut Latinas [Doctorial disseration]. Accessed from: http://opencommons.uconn.edu/dissertations/AAl3265779/. Accessed 29 Jan 2018.

39. Lu MC, Tache V, Alexander GR, Kotelchuck M, Halfon N. Preventing low birth weight: is prenatal care the answer? J Matern Fetal Neonatal Med. 2003; 13(6):362-80.

\section{Ready to submit your research? Choose BMC and benefit from:}

- fast, convenient online submission

- thorough peer review by experienced researchers in your field

- rapid publication on acceptance

- support for research data, including large and complex data types

- gold Open Access which fosters wider collaboration and increased citations

- maximum visibility for your research: over $100 \mathrm{M}$ website views per year

At BMC, research is always in progress.

Learn more biomedcentral.com/submissions 